Supporting Information (SI)

for

\title{
Specific Core-Satellite Nanocarriers for Enhanced Intracellular ROS Generation and Synergistic Photodynamic Therapy
}

Tingting Shen, ${ }^{1 \#}$ Xiaoxiao Hu, ${ }^{2 \#}$ Yongchao Liu, ${ }^{1}$ Yu Zhang, ${ }^{3}$ Kun Chen, ${ }^{1}$ Sitao Xie, ${ }^{1}$ Guoliang Ke, ${ }^{1 *}$ Guosheng Song, ${ }^{1}$ Xiao-Bing Zhang ${ }^{1 *}$

${ }^{1}$ Molecular Sciences and Biomedicine Laboratory, State Key Laboratory for Chemo/Biosensing and Chemometrics, College of Chemistry and Chemical Engineering and College of Biology, Collaborative Innovation Center for Molecular Engineering and Theranostics, Hunan University, Changsha 410082, China.

${ }^{2}$ College of Life Sciences, Molecular Science and Biomedicine Laboratory (MBL), State Key Laboratory of Chemo/Bio-Sensing and Chemometrics, Aptamer Engineering Center of Hunan Province, Hunan University, Changsha, Hunan, 410082, China

${ }^{3}$ Key Laboratory of Molecular Nanostructure and Nanotechnology, CAS Research/Education Center for Excellence in Molecular Sciences, Institute of Chemistry, Chinese Academy of Sciences, Beijing, 100190, China

* To whom correspondence should be addressed:

E-mail: xbzhang@hnu.edu.cn,glke@hnu.edu.cn. 


\section{S1. Experimental Section}

Materials. $\mathrm{Er}\left(\mathrm{CF}_{3} \mathrm{COO}\right)_{3} \cdot \mathrm{xH}_{2} \mathrm{O}, \quad \mathrm{Nd}\left(\mathrm{CF}_{3} \mathrm{COO}\right)_{3} \cdot \mathrm{xH}_{2} \mathrm{O}, \quad \mathrm{Gd}\left(\mathrm{CF}_{3} \mathrm{COO}\right)_{3} \cdot \mathrm{xH}_{2} \mathrm{O}$ and $\mathrm{Yb}\left(\mathrm{CF}_{3} \mathrm{COO}\right)_{3} \cdot \mathrm{xH}_{2} \mathrm{O}$ were prepared by reacting $\mathrm{Nd}_{2} \mathrm{O}_{3}, \mathrm{Er}_{2} \mathrm{O}_{3}, \mathrm{Gd}_{2} \mathrm{O}_{3}$ and $\mathrm{Yb}_{2} \mathrm{O}_{3}$ (99.99\%, Sigma) with trifluoroacetic acid and then removing superfluous trifluoroacetic acid. Sodium trifluoroacetate $\left(\mathrm{CF}_{3} \mathrm{COONa}\right)$, 1-Octadecene (ODE), Oleic acid (OA), silicon phthalocyanine dihydroxide (SPCD), nonylphenylether (CO-520), Tetraethyl orthosilicate (TEOS), N-(trimethoxysilylpropyl) ethylenediamine triacetic acid (CPTS), 1,3-diphenylisobenzofuran (DPBF), Cetyltrimethylammonium bromide (CTAB), [3-(Dimethylamino)propyl]-3-ethylcarbodiimide hydrochloride (EDC), N-Hydroxysulfosuccinimide (Sulfo-NHS), Chloroauric acid $\left(\mathrm{HAuCl}_{4}\right)$, Sodium citrate, 1-octadecene (90\%) were purchased from Sigma Aldrich and J\&K Chemical Ltd. All reagents were of analytical grade and used without any purification. MilliQ water was used throughout the experiments.

Methods and instruments. Dynamic light scattering (DLS) measurements were conducted on Zetasizer Nanoseries (Nano ZS90). Fourier transform infrared (FTIR) spectra of the materials were conducted within the $4000-400 \mathrm{~cm}^{-1}$ wavenumber range by using a Nicolet 6700 FTIR spectrometer with the $\mathrm{KBr}$ pellet technique. Transmission electron microscopy (TEM) images were obtained by using a JEM-2010 (JEOL). UV-Vis spectra were recorded on a UV-2450 spectrophotometer (Shimadzu). The luminescence spectra were measured on a Fluoromax-4 spectrofluorometer (HORIBA Jobin Yvon, Edison, NJ). Three parallel measurements were carried out for 
each sample. All measurements were carried out at room temperature.

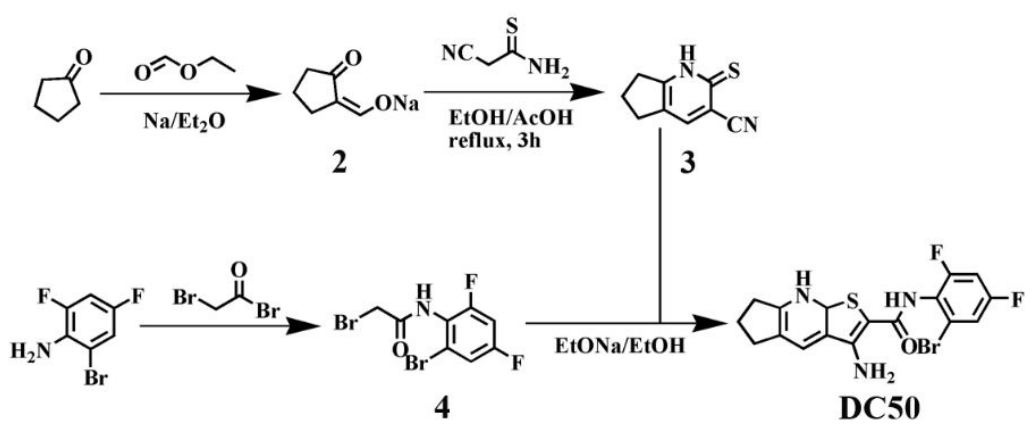

Scheme S1. The synthetic route of DC50.

Synthesis of DC50: Sodium $(1.91 \mathrm{~g}, 83 \mathrm{mmol})$ was added into $200 \mathrm{~mL}$ of dry ether in a 1-L round bottom flask, and the suspension was cooled to $0{ }^{\circ} \mathrm{C}$ in an ice bath. To this cooled suspension was added a mixture of ethyl formate $(6.15 \mathrm{~g}, 0.083 \mathrm{~mol})$ and cyclopentanone $(6.89 \mathrm{~g}, 0.083 \mathrm{~mol})$ in dry ether $(100 \mathrm{~mL})$. The temperature of the reaction mixture was allowed to reach room temperature, and stirring was continued overnight. The crude suspension was filtered, and the precipitate was dried under vacuum for $2 \mathrm{~h}$ to obtain crude sodium salt 2 .

Glacial AcOH $(0.57 \mathrm{~mL}, 10 \mathrm{mmol})$ was added to a solution of sodium salt $2(2.68 \mathrm{~g}$, $20 \mathrm{mmol}$ ) in $10 \mathrm{~mL}$ of ethanol, and cyanothioacetamide (2.00 g, $20 \mathrm{mmol}$ ) was added at $50^{\circ} \mathrm{C}$. After additional $\mathrm{AcOH}(0.57 \mathrm{~mL}, 10 \mathrm{mmol})$ was added, the mixture was heated to reflux for $3 \mathrm{~h}$. The precipitate was filtered off, washed with ethanol and hexane, and recrystallized from $\mathrm{AcOH}$ to give compound $\mathbf{3}$.

To a solution of aromatic amine $(1.54 \mathrm{~g}, 7.4 \mathrm{mmol})$ and DMAP $(0.45 \mathrm{~g}, 3.7 \mathrm{mmol})$ in THF was added dropwise to a solution of bromoacetyl bromide (1.49 $\mathrm{g}, 7.4 \mathrm{mmol})$ in THF at $0^{\circ} \mathrm{C}$. After stirred at $0^{\circ} \mathrm{C}$ for $0.5 \mathrm{~h}$, the mixture was stirred for another $1 \mathrm{~h}$ at 
RT. The reaction was quenched with water and extracted with $\mathrm{CH}_{2} \mathrm{Cl}_{2}$, dried over $\mathrm{Na}_{2} \mathrm{SO}_{4}$, filtered, and concentrated by rotary evaporator. Recrystallized from EtOH to afford compound 4 .

To a solution of compound $3(441 \mathrm{mg}, 2.5 \mathrm{mmol})$ and compound 4 (822 mg, 2.5 mmol) in EtOH was added EtONa $(510 \mathrm{mg}, 7.5 \mathrm{mmol})$, the resulting mixture was refluxed for $1.5 \mathrm{~h}$, the solid was collected and recrystallized from ethanol to give the target product DC50. 1H NMR (400 MHz, DMSO-d $\left.d_{6}\right) \delta 9.28(\mathrm{~s}, 1 \mathrm{H}), 8.27(\mathrm{~s}, 1 \mathrm{H})$, $7.61(\mathrm{~d}, J=7.8 \mathrm{~Hz}, 1 \mathrm{H}), 7.49(\mathrm{td}, J=9.3,2.8 \mathrm{~Hz}, 1 \mathrm{H}), 7.28(\mathrm{~s}, 2 \mathrm{H}), 3.08-2.90(\mathrm{~m}$, 4H), 2.28 - $2.06(\mathrm{~m}, 2 \mathrm{H}) .13 \mathrm{C}$ NMR (100 MHz, DMSO- $\left.d_{4}\right) \delta 168.43,164.55,157.85$ $(\mathrm{dd}, \mathrm{J}=239,14 \mathrm{~Hz}), 158.99(\mathrm{dd}, \mathrm{J}=257,16 \mathrm{~Hz}), 157.29,147.38,133.29,126.22$, $125.10(\mathrm{~d}, \mathrm{~J}=12 \mathrm{~Hz}), 123.94,122.69(\mathrm{~d}, \mathrm{~J}=15 \mathrm{~Hz}), 115.67$ (d, J = 26 Hz), 104.23 (t), $94.44,33.61,29.63,23.23$.

Preparation of gold nanoparticles: Gold nanoparticles (AuNP) were synthesized according to the previous method. ${ }^{1}$ Chloroauric acid $\left(\mathrm{HAuCl}_{4}\right)(45 \mathrm{mg})$ was dissolved in $20 \mathrm{~mL}$ of deionized water. The solution was filtered through a $0.22 \mu \mathrm{m}$ regenerated cellulose syringe filter to remove any macroscopic impurities. Deionized water (380 $\mathrm{mL}$ ) was added to the filtered solution, and the mixture was heated to the boiling point. Subsequently, $14 \mathrm{~mL}$ of filtered $(0.22 \mu \mathrm{m} \mathrm{RC}$ syringe filter $) 1 \mathrm{wt} \%$ solution of trisodium citrate was added, and the temperature was kept at the boiling point for another $30 \mathrm{~min}$ before the mixture was allowed to cool to room temperature. The solution was stirred at high speed (250-500 rpm) throughout the synthesis.

Native gel electrophoresis: Prior to each experiment, stock solutions of all the strands 
were annealed and diluted to a concentration of $20 \mu \mathrm{M}$. For each lane, the final concentration of the strands was $5 \mathrm{uM}$ with a total volume of $2.5 \mu \mathrm{L}$ and were supplemented with $0.42 \mu \mathrm{L}$ of $6 \times$ BeyoRed DNA loading buffer from ThermoFisher. PAGE was performed in $1 \times$ TBE buffer solution (0.09 M Tris-boric acid and $0.002 \mathrm{M}$ EDTA) with $12 \%$ native gels. Oligonucleotides $(5 \mu \mathrm{M})$ were loaded on the gel, and electrophoresis was run at $64 \mathrm{~V}$ for $85 \mathrm{~min}$ at room temperature. After electrophoresis, the gel was stained using $1 \times$ SYBR Gold (ThermoFisher), under kept for $5 \mathrm{~min}$ in dark, then lightly rinsed with water and visualized using Bio-RAD ChemiDoc XRS + Imaging System (America).

Drug release experiments: The drug release experiments were carried out with and without NIR laser irradiation $\left(1 \mathrm{~W} \mathrm{~cm} \mathrm{~cm}^{-2}, 808 \mathrm{~nm}\right)$. Firstly, $4 \mathrm{mg}$ of the UPSD@Au nanocomposites was dispersed in $4 \mathrm{~mL}$ of DPBS buffer solutions $(\mathrm{PH}=7.4)$, and the mixture was maintained with slight shaking at $37^{\circ} \mathrm{C}$. At the precalculated time points, the mixture was irradiated for $0 \mathrm{~min}$ or $10 \mathrm{~min}$ and then centrifuged; $2 \mathrm{~mL}$ of supernatant were then removed to test the absorption intensities of DC50 (at $293 \mathrm{~nm}$ ). At the same time, $2 \mathrm{~mL}$ of fresh DPBS buffer solution was supplemented into the initial mixture, which was maintained with magnetic stirring to obtain a uniform dispersion for the next study.

Cell Culture: Human lung adenocarcinoma A549 cells, H1299 cells were cultured in RPMI 1640 medium containing $10 \%$ fetal bovine serum (FBS) at $37^{\circ} \mathrm{C}$ in a humidified 5\% $\mathrm{CO}_{2}$-containing atmosphere. $\mathrm{LO}_{2}$ cells, $\mathrm{HEK}-293$ cells were cultured in DMEM medium containing $10 \%$ fetal bovine serum (FBS) at $37^{\circ} \mathrm{C}$ in a humidified 
$5 \% \mathrm{CO}_{2}$-containing atmosphere.

Western Blot: To collect protein, the harvested H1299 cells, A549 cells, HEK293 cells, and $\mathrm{LO}_{2}$ cells were incubated in RIPA buffer on ice for $20 \mathrm{~min}$, homogenized, and centrifuged at $13000 \mathrm{rpm}$ for $15 \mathrm{~min}$ at $4^{\circ} \mathrm{C}$. Total protein was measured using a NanoDrop 2000 equipment (Thermo, America) and separated on 12\% sodium dodecyl sulfate polyacrylamide gel electrophoresis (SDS-PAGE). The proteins were then transferred to a PVDF membrane $(0.2 \mu \mathrm{m})$, which was incubated in blocking solution containing $5 \%$ skim milk powder at $37^{\circ} \mathrm{C}$ for $2 \mathrm{~h}$ and rinsed with $1 \times$ Tris Buffered Saline Tween 20 (TBST) three times. Subsequently, the membrane was incubated with primary antibodies at $4{ }^{\circ} \mathrm{C}$ overnight and secondary antibodies at room temperature for $2 \mathrm{~h}$. Finally, immunoreactive proteins were visualized, and images were acquired with a Bio-RAD ChemiDoc XRS + Imaging System (America) after staining with a WesternBright ECL kit (advansta, America). $\square$-actin was used as an internal control to normalize protein expression.

Extracellular and intracellular ROS detection: The generation of extracellular ROS was measured with a DPBF probe. Briefly, $2 \mathrm{~mL}$ of ethanol solution containing DPBF (10 mM) was added to $2 \mathrm{~mL}$ of UPSD@Au (10 mg) aqueous solution; then, the mixture was maintained in the dark with magnetic stirring and irradiated with the 808 $\mathrm{nm}$ laser for various time periods. Then, the supernatant was collected for UV-vis detection $(410 \mathrm{~nm})$ on a Shimadzu UV/vis spectrophotometer (UV-2450). The effects of the NIR light irradiation alone and in all contrast, samples were also investigated by the same process. 
HEK293 cells and H1299 cells were firstly seeded in confocal small dish $\left(4 \times 10^{4}\right)$ for $24 \mathrm{~h}$ before further manipulation. The cells were then incubated with DC50 (50 $\mu \mathrm{g}$ mL $\left.{ }^{-1}\right), U P S D @ A u\left(100 \mu \mathrm{g} L^{-1}\right), \mathrm{US} @ A u(100 \mu \mathrm{g} \mathrm{mL}-1), \mathrm{UPS} @ A u\left(100 \mu \mathrm{g} \mathrm{mL} \mathrm{L}^{-1}\right)$, USD@Au $\left(100 \mu \mathrm{g} \mathrm{mL}^{-1}\right)$ for $12 \mathrm{~h}$. The treated cells were washed with DPBS twice and incubated with $20 \mu \mathrm{M}$ of the fluorescent probe DCFH-DA for $30 \mathrm{~min}$. After the un-loaded probe was removed with DPBS twice, the indicated cells were irradiated with an $808 \mathrm{~nm}$ laser for $5 \mathrm{~min}\left(2 \mathrm{~W} \mathrm{~cm}^{-2}\right)$. Finally, the medium was replaced with DPBS, and the fluorescence images of treated cells were acquired using a confocal microscope FV1000 (OLYMPUS, Japan). For DCF detection, the excitation was 488 $\mathrm{nm}$ and the emission wavelength was $525 \mathrm{~nm}$.

Total Copper Content by ICP-MS detection: The total copper content of cells incubated for $12 \mathrm{~h}$ with media having different samples (10 $\mu \mathrm{M}$ DC50) were determined using ICP-mass spectroscopy. We collected $5 \times 10^{6}$ cells in $150 \mu \mathrm{L}$ PBS buffer for total $\mathrm{Cu}$ uptake experiments and acidified with $200 \mu \mathrm{L} 70 \%$ nitric acid incubated $12 \mathrm{~h}$ at $80^{\circ} \mathrm{C}$, diluted to $5 \mathrm{~mL}$ by $\mathrm{H}_{2} \mathrm{O}$, and used for analysis.

Cellular cytotoxicity assay (CCK-8): For the cytotoxicity evaluation, the CCK-8 assay was used with H1299 and HEK293 cells. Briefly, the cells were seeded in a 96-well plate at a density of $1.5 \times 10^{4}$ cells per well, cultured with fresh RPMI-1640 medium, and supplemented with $10 \%$ FBS under a humidified $5 \% \mathrm{CO}_{2}$ atmosphere at $37^{\circ} \mathrm{C}$ for $12 \mathrm{~h}$. After that, various concentrations of samples were added to the culture wells, and each well was irradiated with an $808 \mathrm{~nm}$ laser for $0 \mathrm{~min}$ or $5 \mathrm{~min}$; then, the cells were further incubated for $24 \mathrm{~h}$. Subsequently, the cells were exchanged with $100 \mu \mathrm{L}$ 
of fresh culturing medium, followed by adding $10 \mu \mathrm{L}$ CCK-8 solution to each well. The plates were cultured again at $37^{\circ} \mathrm{C}$ for $0.5 \mathrm{~h}$ in an incubator. Finally, the absorption at $450 \mathrm{~nm}$ was measured by a plate reader (Synergy 2 multimode microplate reader). Untreated cancer cells were used as control samples. The percentages of cell viabilities were calculated using the optical densities with respect to the control values.

In vivo investigation: Female Balb/c mice $(\sim 20 \mathrm{~g})$ were obtained from Hunan SJA Laboratory Animal Co., Ltd. and used under protocols approved by Hunan University Laboratory Animal Center. The H1299 tumor model was obtained for the therapy evaluation by subcutaneously inoculating H1299 cells $\left(\sim 8 \times 10^{6}\right)$ into the right thigh of each nude mice. After the tumors had developed to about $200 \mathrm{~mm}^{3}$, the tumor-bearing mice were randomly divided into seven groups and were treated by intratumoral injection with DPBS without NIR irradiation, DPBS with NIR irradiation, UPSD@Au without NIR irradiation, UPSD@Au with NIR irradiation, US@Au with NIR irradiation,UPS@Au with NIR irradiation,or USD@Au with NIR irradiation. For all the samples, the injection doses are $5 \mathrm{mg} / \mathrm{Kg}$. After $0.5 \mathrm{~h}$ post-injection, seven sets of mice were irradiated by the NIR laser $\left(808 \mathrm{~nm}, 1 \mathrm{~W} / \mathrm{cm}^{2}\right)$ for $0 \mathrm{~min}$ or $10 \mathrm{~min}$. The NIR irradiation was carried out again after $24 \mathrm{~h}$ post-injection. The tumor volume and body weight of each mouse were monitored every two days in the groups with or without NIR laser irradiation $\left(808 \mathrm{~nm}, 1 \mathrm{~W} / \mathrm{cm}^{2}\right)$ for 14 days. The tumor volume was calculated as length $\times(\text { width })^{2} \times 1 / 2$ with a caliper. The liver, kidney, spleen and tumor tissues of the mice in the control group and treatment group were isolated and 
sectioned into slices for histological analysis by H\&E staining. Slides were recorded using a Pannoramic MIDI digital slide scanner with Zeiss plan-apochromat objective (magnification: 20x, Numerical aperture: 0.8) and Hitachi (HV-F22CL) 3CCD progressive scan colour camera (resolution: $0.2325 \mu \mathrm{m} / \mathrm{pixel}$ ).

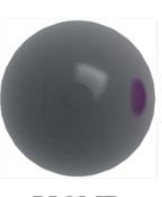

UCNPs
SPCD

TEOS

TEOS

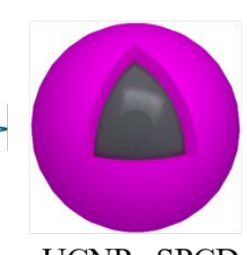

UCNPs-SPCD

(UP) (UPS)

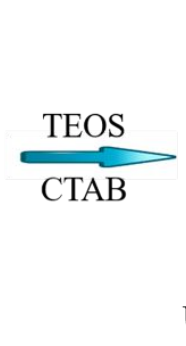

O: DC50 r

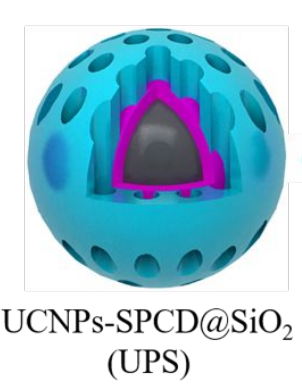

sDNA

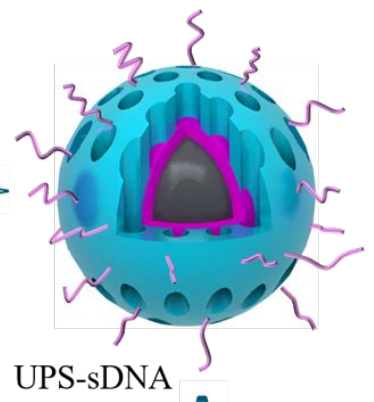

NIR

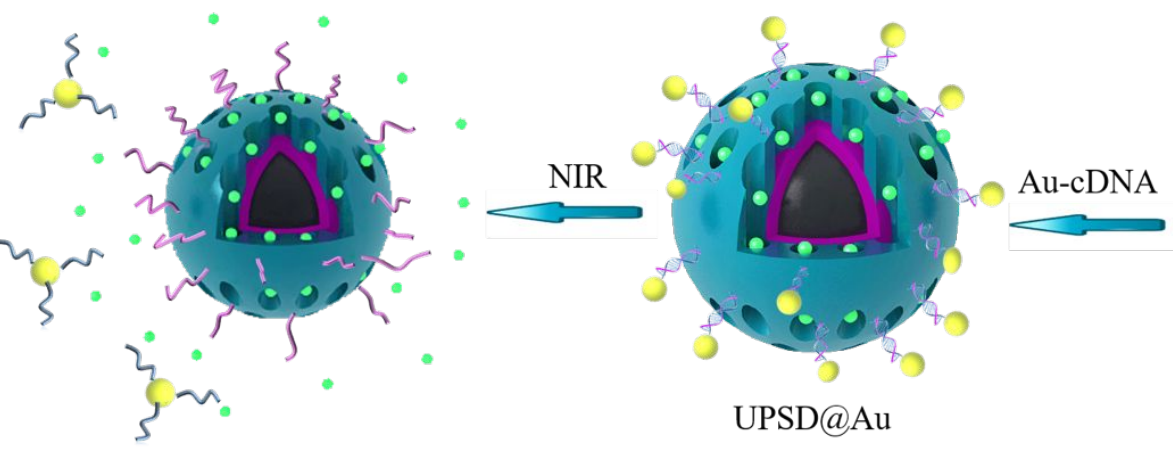

(UPSD-sDNA)

Figure S1. Schematic illustration of the synthesis of UPSD@Au nanoparticles. 


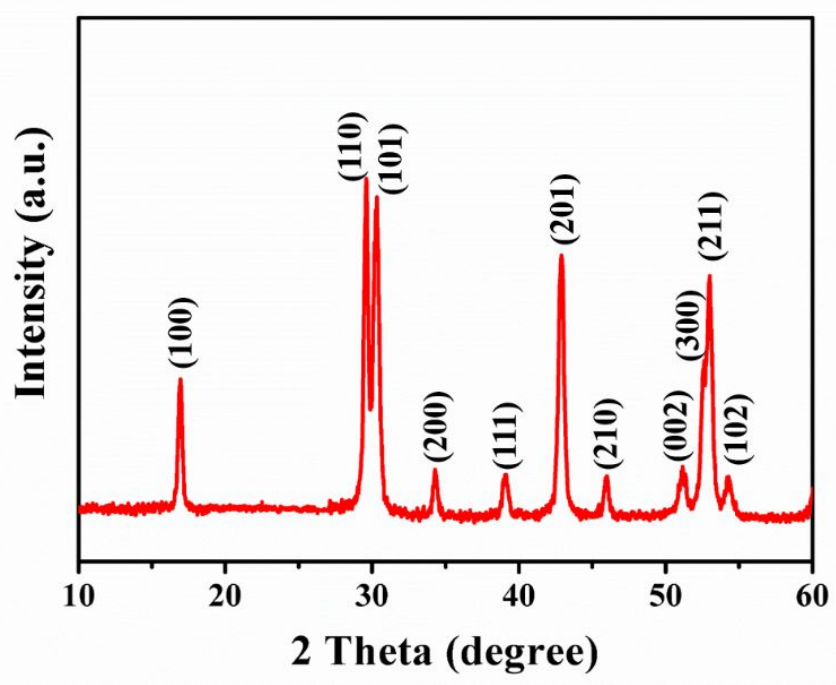

Figure S2. X-ray diffraction spectra of UCNPs

$\left(\mathrm{NaGdF}_{4}: \mathrm{Yb}^{3+}: \mathrm{Er}^{3+} @ \mathrm{NaGdF}_{4}: \mathrm{Yb}^{3+}: \mathrm{Nd}^{3+}\right)$.

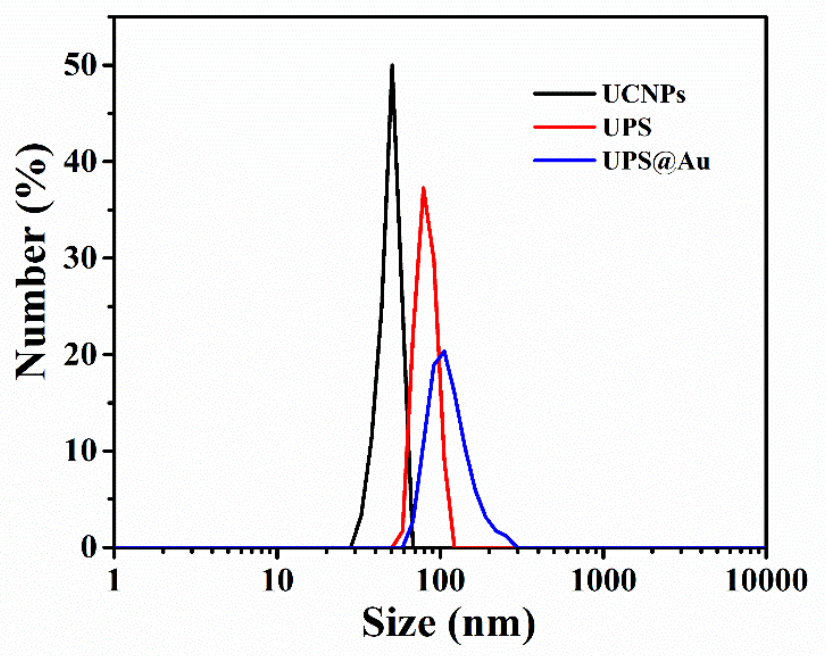

Figure S3. Dynamic light scattering (DLS) of UCNPs, UPS and UPS@Au. 


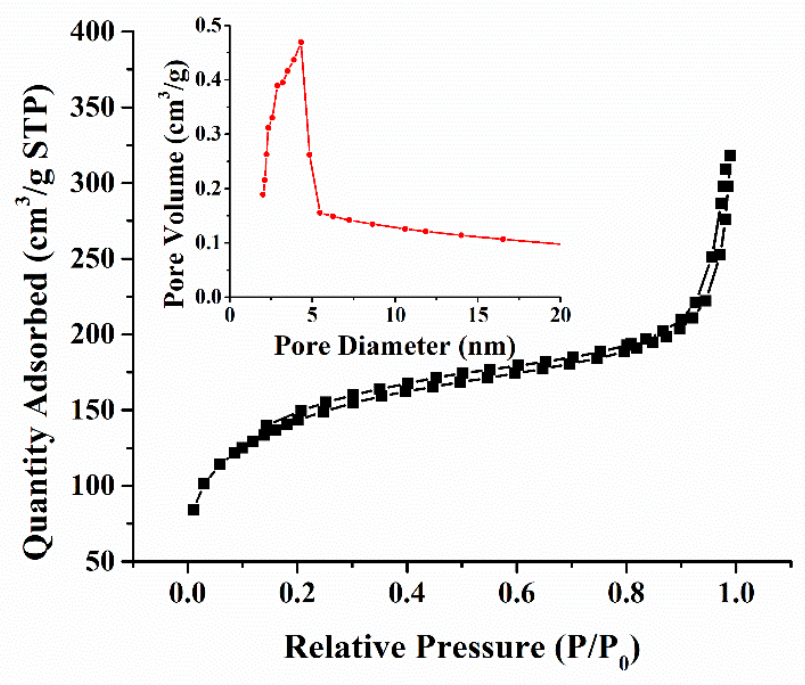

Figure S4. $\mathrm{N}_{2}$ adsorption/desorption isotherms of UPS (inset : pore size distribution from adsorption branch). The results showed that the silica shell had an average pore size of $4.1 \mathrm{~nm}$ and the surface area was estimated to be $478.9 \mathrm{~m}^{2} / \mathrm{g}$ according to the Barret-Joyner-Halenda (BJH) theory.

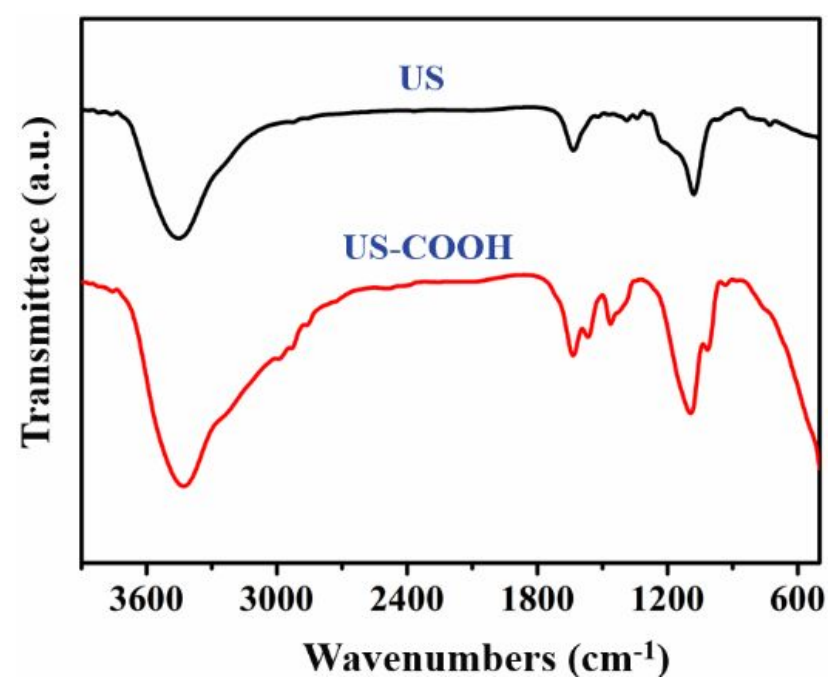

Figure S5. The FTIR of US and US-COOH. 


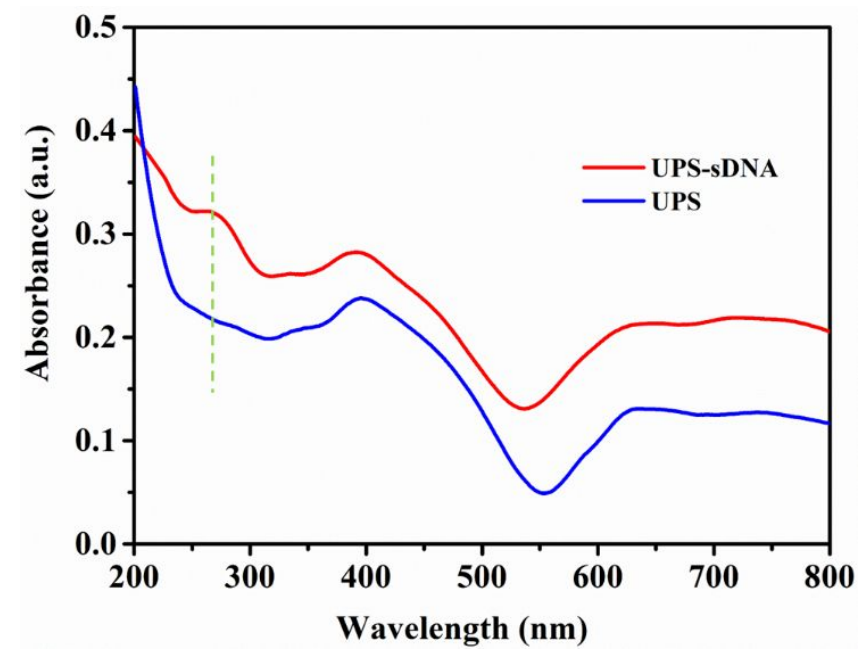

Figure S6. UV-vis absorption spectra of UPS and UPS-sDNA.

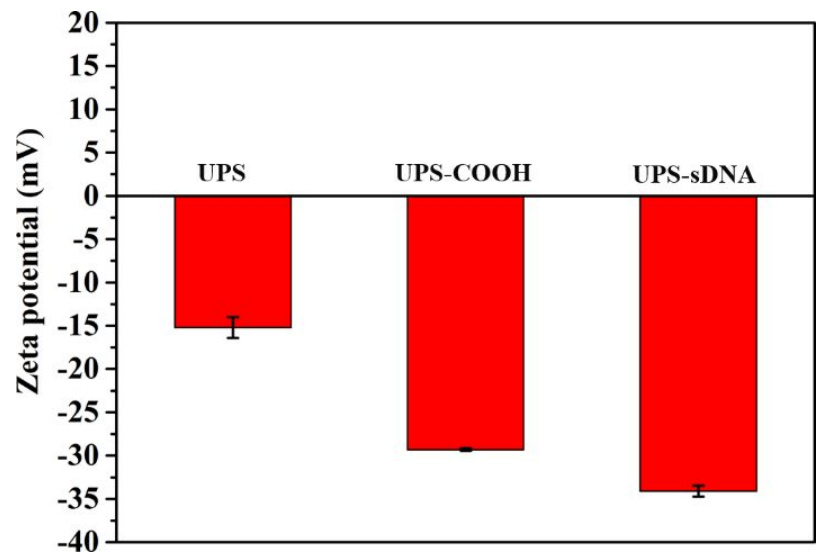

Figure S7. The zeta potential of UPS, UPS-COOH and UPS-sDNA are $-15.2 \mathrm{mV}$, $-29.3 \mathrm{mV}$, and $-34.1 \mathrm{mV}$. 


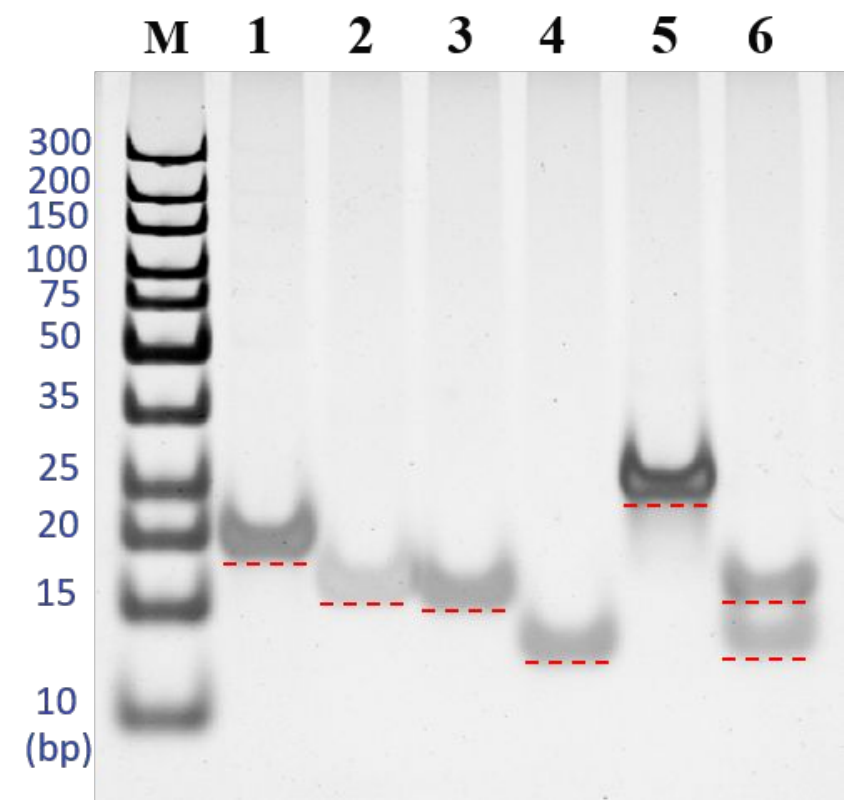

Figure S8. Analysis of DNA hybridization by native polyacrylamide gel electrophoresis. Lane1 is strand Au-15 (cDNA), lane 2 is strand UPS-15 (sDNA), lane 3 is strand Au-9 (cDNA), lane 4 is UPS-9 (sDNA), lane 5 is Au-15 + UPS-15, lane 6 is Au-9 + UPS-9. The DNA ladder were purchased from ThermoFisher. For better understanding the influence of DNA length on hybridization efficiency, two pairs of DNA were prepared including Au-15 (cDNA: 5'-SH-tttttt TTG TGG TGG TGG TGG-3') and UPS-15 (sDNA: 5'-NH ${ }^{\circ}$-ttttt CCA CCA CCA CCA CAA-3'), Au-9 (cDNA: 5'-SH-tttttt TTG TGG TGG-3') and UPS-9 (sDNA: 5'-NH ${ }_{2}$-tttttt CCA CCA CAA-3 ${ }^{\circ}$ ). Finally, the gel show that the length of 15 is optimum while the length of 9 didn't hybridized. 


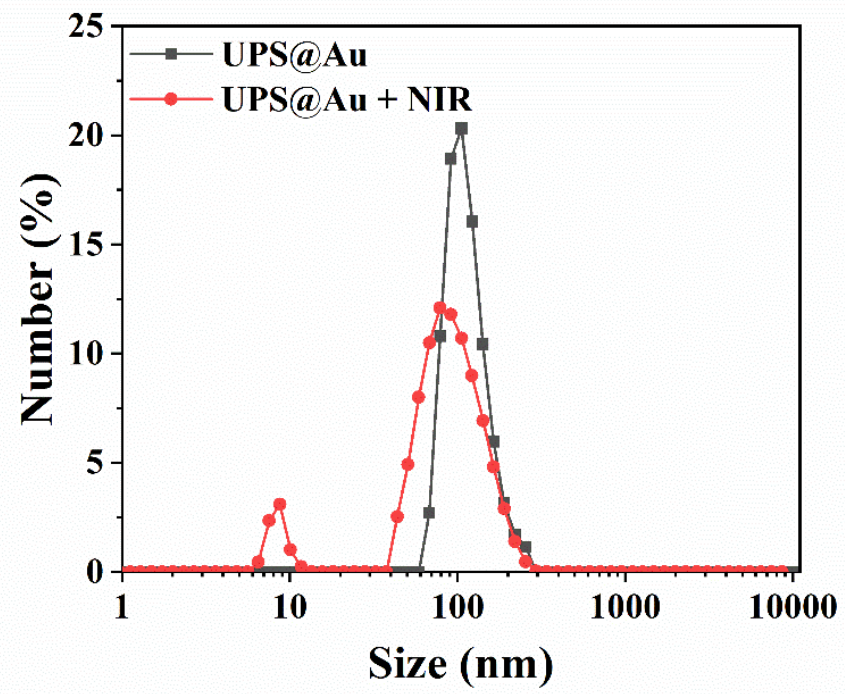

Figure S9. Dynamic light scattering (DLS) of UPS@Au (1 mg/mL) before and after NIR irradiation (10 $\left.\mathrm{min}, 2 \mathrm{~W} / \mathrm{cm}^{2}\right)$.

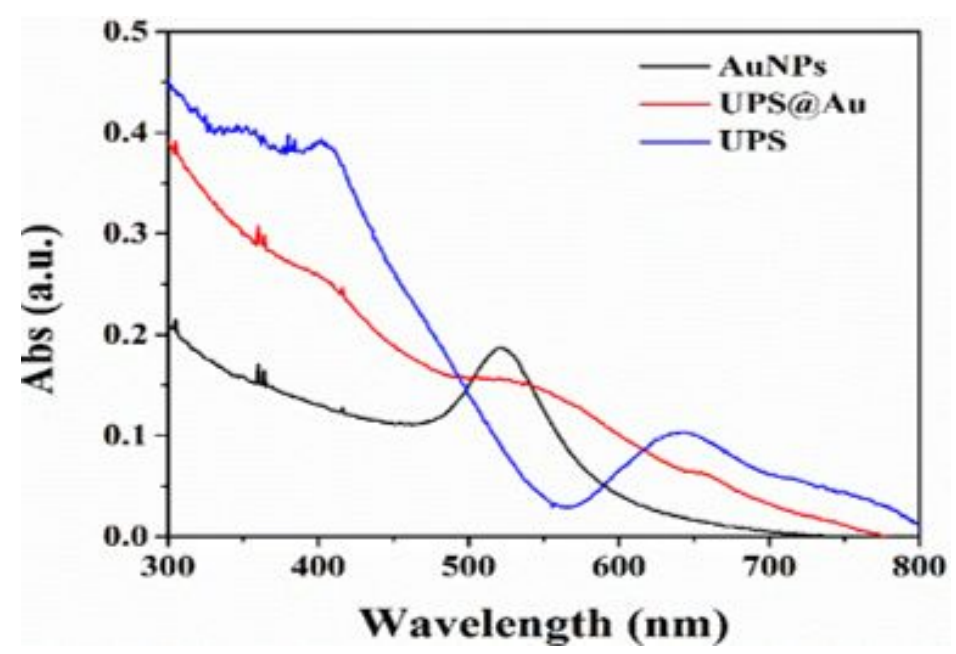

Figure S10. UV-vis absorption spectra of Au NPs, UPS, and UPS@Au. 


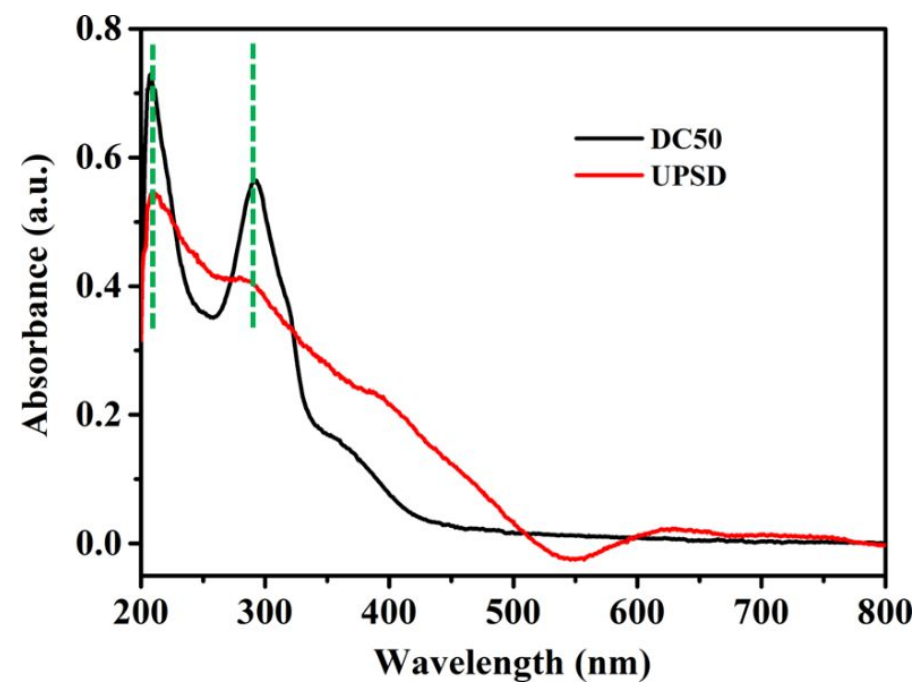

Figure S11. UV-Vis absorption spectra of DC50 and UPSD in ethanol.

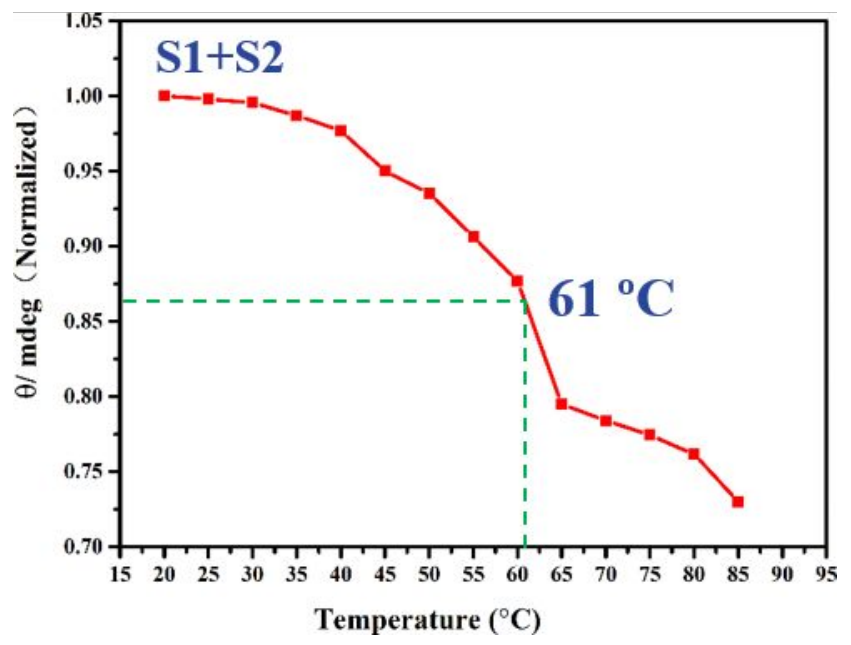

Figure S12. The CD melting curves at $280 \mathrm{~nm}$ for $10 \mu \mathrm{mol}$ of $\mathrm{S} 1+\mathrm{S} 2$ in TM buffer (10 mM). 

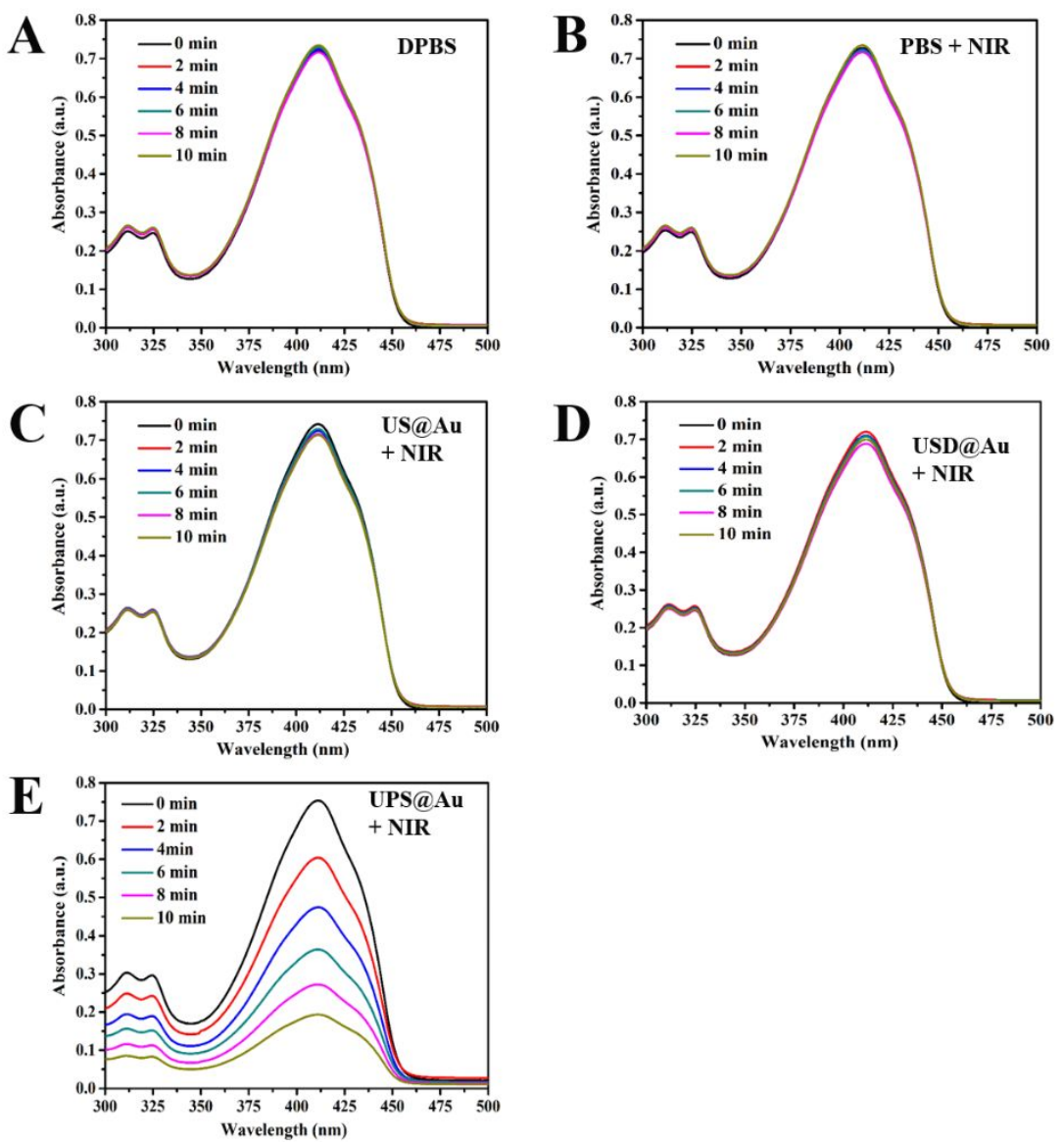

Figure S13. The absorbance spectra of DPBF mixed with (A)DPBS, (B)DPBS +808 nm, (C) US@Au + 808 nm,(D) USD@Au + 808 nm, (E)UPS@Au + 808 nm at different time points. 


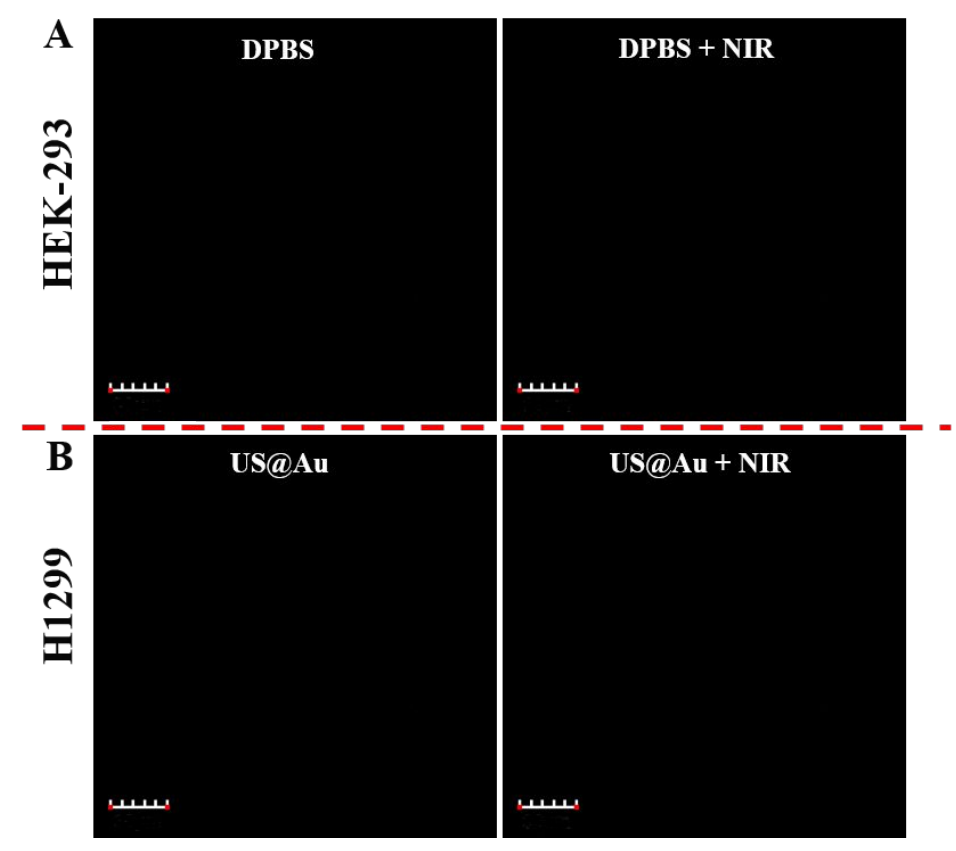

Figure S14. Fluorescence confocal laser scanning microscopy images showing intracellular ROS generation in (A) HEK-293 cells and (B) H1299 cells with oxidized DCF fluorescence under treatment with DPBS and US@Au with or without laser irradiation (green fluorescence from DCF indicates the presence of singlet oxygen). All the laser pump powers were $2 \mathrm{~W} / \mathrm{cm}^{2}$. Excitation wavelength $=488 \mathrm{~nm}$; emission wavelength $=515 \pm 35 \mathrm{~nm}$. Scale bar $=30 \mu \mathrm{m}$.

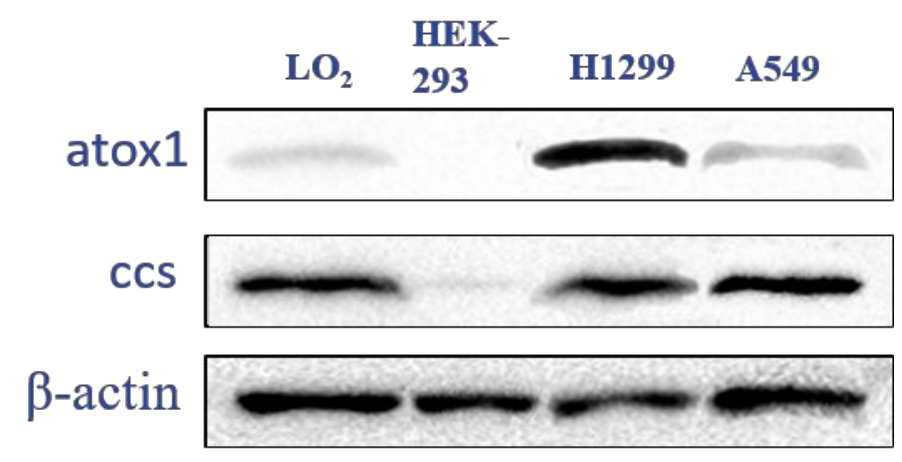

Figure S15. The expression levels of Atox 1 and CCS are investigated in different cells by western blot. $\beta$-actin expression was used as a loading control. 


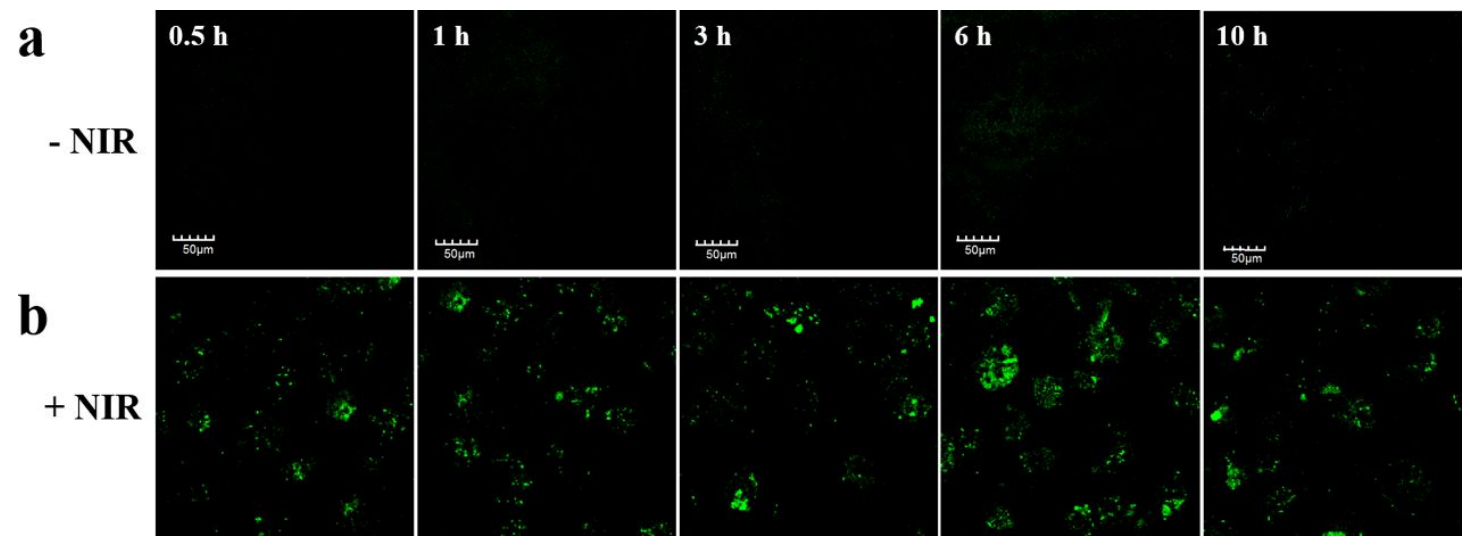

Figure S16. Confocal fluorescence images of H1299 cells incubated with UPSD@Au

(a) before irradiation and (b) after $808 \mathrm{~nm}$ laser light irradiation $\left(2 \mathrm{~W} / \mathrm{cm}^{2}, 5 \mathrm{~min}\right)$.

Excitation wavelength of confocal laser $=808 \mathrm{~nm}$; emission wavelength $=500-580$ nm. Scale bar $=50 \mu \mathrm{m}$.

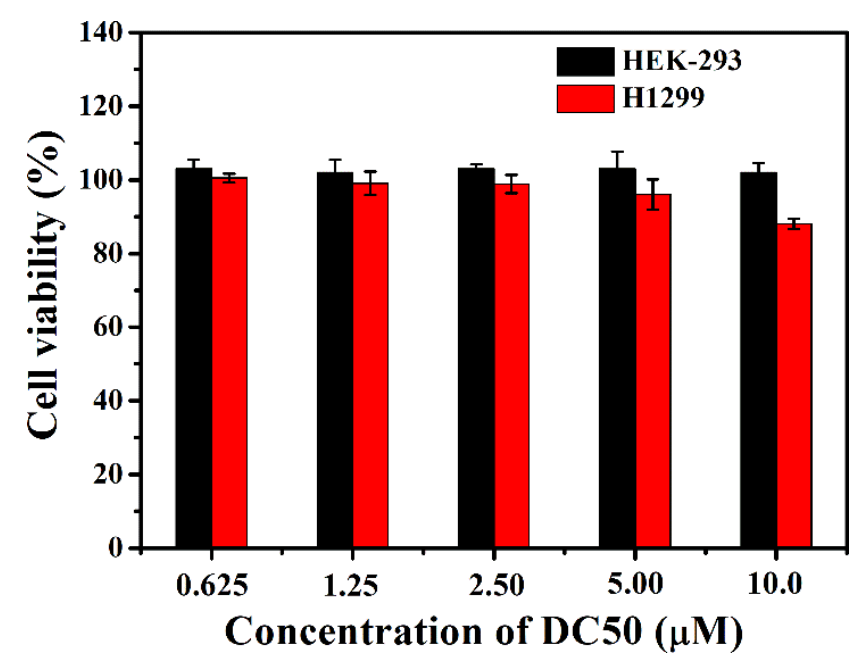

Figure S17. Cytotoxicity of DC50 on HEK-293 and H1299 cells for 24 h treated by indicated concentrations. 


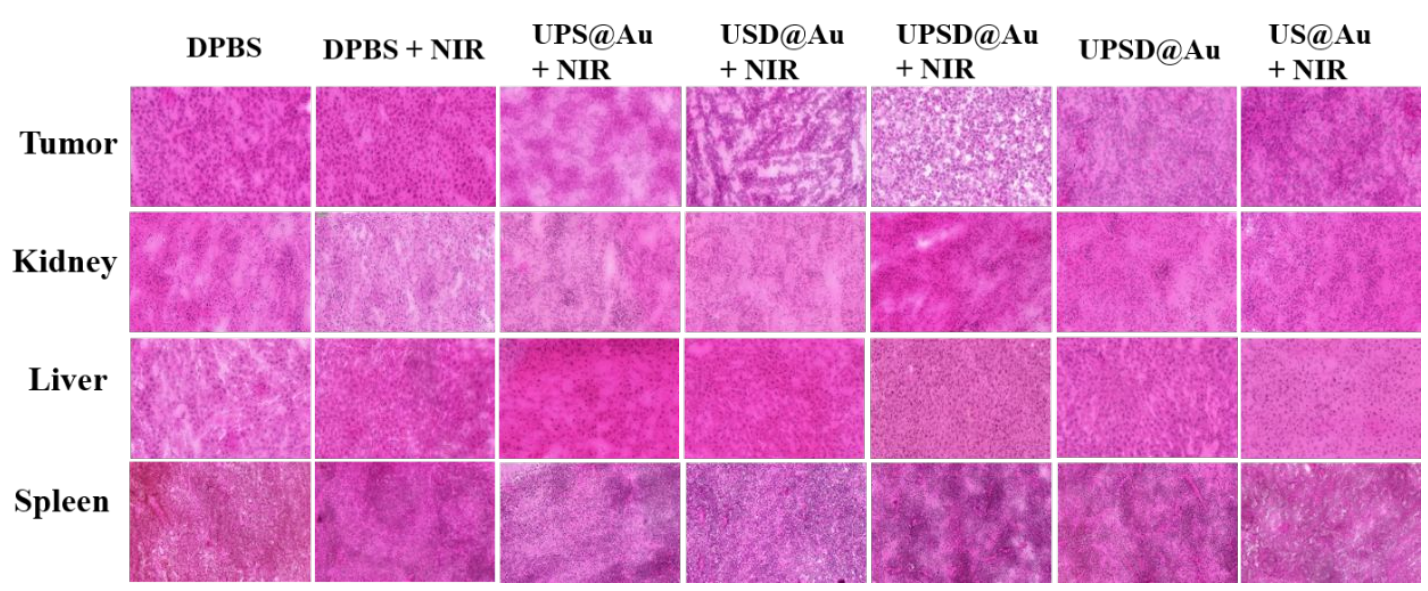

Figure S18. Hematoxylin and eosin (H\&E)-stained slices of tumors and various major organs taken from the therapy and control groups after 14 days of treatment.

\section{References}

1. Moerz, S. T.; Kraegeloh, A.; Chanana, M.; Kraus, T., Formation Mechanism for Stable Hybrid Clusters of Proteins and Nanoparticles. ACS Nano 2015, 9 (7), 6696-6705. 